1

\title{
Experimental validation of a 2D overland flow model using high resolution water depth and velocity data
}

\author{
L. Cea ${ }^{* 1}$, C. Legout ${ }^{2}$, F. Darboux ${ }^{3}$, M. Esteves ${ }^{4}$, G. Nord $^{2}$
}

\section{Abstract}

This paper presents a validation of a two-dimensional overland flow model using empirical laboratory data. Unlike previous publications in which model performance is evaluated as the ability to predict an outlet hydrograph, we use high resolution $2 \mathrm{D}$ water depth and velocity data to analyze to what degree the model is able to reproduce the spatial distribution of these variables. Several overland flow conditions over two impervious surfaces of the order of one square meter with different micro and macro-roughness characteristics are studied. The first surface is a simplified representation of a sinusoidal terrain with three crests and furrows, while the second one is a mould of a real agricultural seedbed terrain. We analyze four different bed friction parameterizations and we show that the performance of formulations which consider the transition between laminar, smooth turbulent and rough turbulent flow do not improve the results obtained with Manning or Keulegan formulas for rough turbulent flow. The simulations performed show that using Keulegan formula with a physically-based definition of the bed roughness coefficient, a two-dimensional shallow water model is able to reproduce satisfactorily the flow hydrodynamics. It is shown that, even if the resolution of the topography data and numerical mesh are high enough to include all the small scale features of the bed surface, the roughness coefficient must account for the macro-roughness

*E.T.S. Ingenieros de Caminos Canales y Puertos, Universidad de A Coruña, 15071, A Coruña,

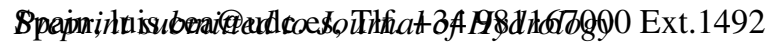

March 4, 2014

${ }^{1}$ Environmental and Water Engineering Group (GEAMA), Civil Engineering School, University of A Coruña, Spain

${ }^{2}$ UJF-Grenoble 1 /CNRS / G-INP / IRD, LTHE UMR 5564, Grenoble, F-38041, France

${ }^{3}$ INRA, UR0272, UR Science du sol, Centre de recherche Val de Loire, CS 40001, F-45075 
characteristics of the terrain in order to correctly reproduce the flow hydrodynamics.

Key words: overland flow, 2D shallow water equations, bed roughness, Large

Scale Particle Image Velocimetry, laser scanner

\section{INTRODUCTION}

locity, which might be used in contaminant transport and erosion models. In fact, there has been a trend in the last years to develop physically-based water erosion and solute transport models including the representation of processes at their lowest scales (Hairsine and Rose, 1992b,a; Jomaa et al., 2010; Nord and Esteves, 2007, 2010; Shaw et al., 2006, 2009). These models use formulations that require a very detailed spatial characterization of the flow field (water depth, velocity and bed friction) in order to take advantage of their full potential. The problem of predicting flow transport capacity demands not only a proper sediment transport equation, but a reliable means of modelling overland flow hydraulics on rough 
surfaces (Abrahams et al., 1998). In this vein, several studies have been devoted to the physical characterization of bed roughness in order to improve the prediction capability of overland flow models (Jarvela, 2002; Shaw et al., 2009), and it has been recognized in previous laboratory studies involving overland flow conditions that the effective bed roughness coefficient varies substantially with the flow properties due to additional head losses generated by small scale flow features which are not resolved in the numerical models (Fraga et al., 2013; Howes et al., 2006; Lawrence, 2000; Shaw et al., 2006; Tatard et al., 2008).

However, an accurate prediction of the outlet hydrograph does not guarantee that the hydraulics within the plot is properly computed, and so such an approach is not a thorough model validation. One of the main conclusions of the work of Tatard et al. (2008) was that the Froude number was not predicted by any of the three models tested on a $40 \mathrm{~m}^{2}$ plot and even the general pattern was missed. This highlights the need to evaluate the performance of two-dimensional overland flow models in terms of their capability to reproduce the spatial distribution of water depth and velocity at the same time. Until now, very few studies have made such evaluation. Tatard et al. (2008) compared measured and modelled depths and velocities at selected points without performing a comparison on the whole plot. More recently, Mügler et al. (2011) intended to make an evaluation of what occurs within the plot by comparing measured and modelled tracer breakthrough curves of point-source injection of tracer under rainfall conditions. Such an approach aims at assessing if the actual travel time of a tracer is well reproduced by the model. However, it is a spatially integrated approach that does not allow the direct comparison of observed and modelled depth-velocity maps at the mesh size scale. To the best of our knowledge, the work presented in this paper provides 
for the first time a direct comparison of modelled and measured water depth and velocity fields under surface runoff conditions. We present the experimental validation of a distributed overland flow model based on the two-dimensional shallow water equations using Large Scale Particle Image Velocimetry (LSPIV) data for the surface velocity and laser scanner data for the water depth. Six test cases over two impervious surfaces with different micro and macro-roughness characteristics are used to validate the model, and to analyze the sensitivity of model performance to the bed friction parameterization and to the spatial resolution of the DTM and numerical mesh. In all the test cases the water depth was always less than $10 \mathrm{~mm}$.

\section{NUMERICAL MODEL AND SOLVER}

Overland flow models based on the two-dimensional shallow water equations solve the following depth-averaged mass and momentum conservation equations:

$$
\begin{aligned}
\frac{\partial h}{\partial t}+\frac{\partial q_{x}}{\partial x}+\frac{\partial q_{y}}{\partial y} & =0 \\
\frac{\partial q_{x}}{\partial t}+\frac{\partial}{\partial x}\left(\frac{q_{x}^{2}}{h}+\frac{g h^{2}}{2}\right)+\frac{\partial}{\partial y}\left(\frac{q_{x} q_{y}}{h}\right) & =-g h \frac{\partial z_{b}}{\partial x}-\frac{\tau_{b, x}}{\rho} \\
\frac{\partial q_{y}}{\partial t}+\frac{\partial}{\partial x}\left(\frac{q_{x} q_{y}}{h}\right)+\frac{\partial}{\partial y}\left(\frac{q_{y}^{2}}{h}+\frac{g h^{2}}{2}\right) & =-g h \frac{\partial z_{b}}{\partial y}-\frac{\tau_{b, y}}{\rho}
\end{aligned}
$$

where $z_{b}$ is the bed elevation, $h$ is the water depth, $\left(q_{x}, q_{y}\right)$ are the two components of the unit discharge, $\left(\tau_{b, x}, \tau_{b, y}\right)$ are the two horizontal components of the bed friction stress, $\rho$ is the water density and $g$ is the gravity acceleration. Turbulent shear stresses have been neglected in Equations (2-3) because under runoff conditions, with water depths of a few millimetres, their influence in the momentum equations is negligible compared to bed friction. 
The bed friction stress in Equations (2-3) can be expressed as:

$$
\frac{\tau_{b, x}}{\rho}=C_{f}|\mathbf{U}| U_{x} \quad \frac{\tau_{b, y}}{\rho}=C_{f}|\mathbf{U}| U_{y}
$$

where $|\mathbf{U}|$ is the modulus of the depth-averaged horizontal velocity, $\left(U_{x}, U_{y}\right)$ are the two horizontal components of the depth-averaged velocity, and $C_{f}$ is a friction coefficient. Several bed friction formulations have been considered in the simulations presented in this paper, including the formulas of Keulegan, Manning and Darcy for rough turbulent flow, the formula of Colebrook-White for smooth and rough turbulent flow, and the formula for laminar flow (Table 1).

The shallow water equations are solved with a finite volume solver. The numerical schemes used in the solver assure the conservation of mass, so that no water is lost or gained during the computation due to numerical errors. The convective terms are discretized with an explicit high-order Godunov type scheme based on Roe's approximate Riemman solver (LeVeque, 2002). Godunov schemes are commonly used in shallow water codes because they can deal efficiently with the development of shock waves, providing accurate and stable results (Toro, 2001). This is especially interesting in rapidly varying flow applications, where regions of subcritical and supercritical flows coexist, as it is the case of overland flow over a complex topography. The bed elevation and bed friction terms in the momentum equations are discretized with the upwind scheme presented in Cea and VázquezCendón (2012). A semi-implicit discretization scheme is used for the bed friction to enhance the numerical stability of the solver. In order to model the wetting and drying of certain regions of the spatial domain, the control volumes are allowed to wet and dry during the simulation. For that purpose a wet-dry tolerance parameter is defined, such that if the water depth in a cell is lower than this tolerance the cell is considered to be dry. The water depth is never forced to be zero, in order to 
keep the mass conservation property of the scheme. In all the simulations presented in this paper the wet-dry tolerance parameter was set to $0.01 \mathrm{~mm}$. Model output was insensitive to further reductions of this value. A detailed description of the numerical schemes used in the solver can be found in Cea et al. (2010a) and in Cea and Vázquez-Cendón (2012).

\section{EXPERIMENTAL TEST CASES AND DATASETS}

\subsection{Experimental test cases}

Two moulds of terrain with different complexity were used in the laboratory experiments, which will be referred to as sinusoidal mould (Figure 1) and agricultural mould (Figure 2a). The sinusoidal mould is a square of $1.20 \mathrm{~m}$ by $1.20 \mathrm{~m}$ which consists of three parallel crests and furrows with a sinusoidal shape, with a wave length of $0.20 \mathrm{~m}$ and an amplitude of $0.01 \mathrm{~m}$. The DTM was measured with a spatial resolution of $0.5 \mathrm{~mm}$. The surface of the sinusoidal mould is made of a thin layer of sand with a mean diameter of approximately 0.5-1.0 mm, which is glued to an impervious surface. Therefore, there is no infiltration in the experiments. We will refer by micro-roughness to the bed roughness linked to the sand texture. The water supply was located on the upper part of the surface. The inlet was $0.10 \mathrm{~m}$ wide and was set perpendicular to the direction of the largest slope on each test case. Four different combinations of flow rates and slopes on the sinusoidal mould have been considered for model validation (Table 2). The slopes in the $\mathrm{X}$ - and Y-directions as well as the input flow rates were selected experimentally to obtain specific conditions that would help in assessing the quality of the modelling results. In the different test cases water flows in 1, 2 or 3 furrows, while always being at the limit of overflowing to the next one. For these experi- 
mental conditions the water depth was less than $10 \mathrm{~mm}$ in the whole mould. The Reynolds number in the main furrows varies between 1000 and 12000, depending on the test case and on the furrow considered, while the Froude number varies between zero and 5, although in most of the mould it is larger than one.

The agricultural mould is a square of $0.60 \mathrm{~m}$ by $0.60 \mathrm{~m}$ representative of a seedbed. The mould is a perfect reproduction of a natural seedbed obtained with a methodology similar to the one presented in Kamphorst and Duval (2001). All the experiments were performed on that single reproduction. It exhibits two main parallel furrows oriented along the X-direction. The width of these furrows is of the order of 0.10-0.15 m (Figure 2e). The surface of the agricultural mould is made of plaster and is therefore much smoother than that of the sinusoidal mould. On the other hand, in the agricultural mould there is a macro-roughness formed by small changes in surface topography, as a result of different sized soil aggregates present in the actual seedbed. In order to determine how the representation of these small topographic changes is affected by the DTM resolution, we have filtered the original DTM using average filters of different size, and we have defined the residual length at each point of the mould as the difference between the original and filtered DTM's. The spatial resolution of the original agricultural mould DTM is $2 \mathrm{~mm}$. A filter of $4 \mathrm{~mm}$ produces almost no effect on the original DTM, which confirms that this resolution is high enough to capture all the topography features. A filter of $8 \mathrm{~mm}$ gives an average residual length of $0.35 \mathrm{~mm}$ and a maximum residual length of $6 \mathrm{~mm}$, which is of the order of magnitude of the water depth. If the filter size is increased to $16 \mathrm{~mm}$ the maximum residual length increases to $12 \mathrm{~mm}$. Larger filters introduce a smoothing effect in the macrotopography and distort the definition of the two main longitudinal furrows (Figure 2c and d). The water was 
supplied on the whole width of the upper part of the surface. However, the water systematically enters the mould through the two main furrows, as indicated by the arrows in Figure 2a. Two combinations of flow rates and slopes in the X-direction on the agricultural mould have been used for model validation (Table 2). These were selected in such a way that water flows either in two separated furrows or in two connected furrows. In this case, only the velocity field was available for model validation.

\subsection{Datasets}

For evaluation and comparison purposes, all measurements were performed at steady state. The flow rates were measured separately at the outlet of each furrow by automatically weighing the volume of water for $20 \mathrm{~s}$ to 2 min depending on the flow rate for the sinusoidal mould. For the agricultural mould, the total flow rates were measured by manual sample collection at the outlet every $2 \mathrm{~min}$.

The maps of flow depth in the sinusoidal mould were obtained after subtraction of two elevation maps acquired successively (i.e., subtraction of the water surface map from the DTM without water). Both elevation datasets were measured using the instantaneous profile laser scanner described in Darboux and Huang (2003) according to the protocol presented in Legout et al. (2012). The spatial resolution was $0.5 \mathrm{~mm}$ in $\mathrm{X}$ - and Y-directions. The uncertainty was experimentally assessed to $0.5 \mathrm{~mm}$ with maximum values of $1 \mathrm{~mm}$. It should be remarked that the maps of flow depths were not measured on the agricultural mould.

The maps of surface velocity measurements were obtained by Large Scale Particle Image Velocimetry. Based on the acquisition of successive images of tracers flowing on the surface, the LSPIV technique estimates the movement of tracer particles between image pairs using a cross-correlation analysis. More details on 
the adaptation of this well-known technique to the case of very shallow flows such as overland flow are presented in Legout et al. (2012). The spatial resolution of the velocity map was $5 \mathrm{~mm}$. The ratios between surface velocities obtained with LSPIV and the average velocity on the water column were estimated in Legout et al. (2012) as 0.8 and 0.9 respectively on the sinusoidal and agricultural mould. In the following section, the velocity measurements were corrected by those ratios for the comparison between the experimental surface velocity and the modelled depth-averaged velocity. The uncertainty of the surface velocities was experimentally assessed to $0.03 \mathrm{~m} / \mathrm{s}$ with maximum values of roughly $0.10 \mathrm{~m} / \mathrm{s}$.

\section{RESULTS AND DISCUSSION}

In this section we analyze the performance of the overland flow model presented in section 2 against the experimental data described in section 3. Model performance is evaluated by comparing the spatial distribution of water depth and velocity. In order to quantify the numerical-experimental agreement, the root mean square error is computed for each simulation. As mentioned in section 3, in the agricultural mould there are no available water depth measurements and therefore, only the velocity field is used for comparison.

\subsection{Mesh convergence}

The mesh size is a critical parameter in any numerical model, as it has important consequences on the accuracy of the results, as well as on the computation time required to solve the model equations. Considering that the level of macro-roughness of the two terrains considered in this study is very different, an independent mesh convergence analysis was performed for each terrain, using for that purpose the flow conditions of the test cases S1 (sinusoidal mould) and A1 
(agricultural mould). Table 3 shows the properties of the different grids used in the mesh convergence analysis.

The topography of the sinusoidal mould is quite smooth and regular and therefore, its main features are well captured even with a rather coarse mesh. On the other hand the agricultural mould has a more irregular topography, including soil aggregates up to $10-20 \mathrm{~mm}$ in size. In this case the mesh size has an important impact on the accuracy of the bed elevation definition. The spatial resolution of meshes A1M2, A1M3 and A1M4 (Table 3) is lower than that of the original DTM and therefore, there is a loss of accuracy in the bed topography used in the numerical model.

In both the sinusoidal and the agricultural terrains, the results obtained with the two finest meshes (S1M1 and S1M2 in the sinusoidal mould and A1M1 and A1M2 in the agricultural mould) are almost identical, and show similar flow patterns to those obtained with meshes S1M3 and A1M3 respectively (Figures 3 and 4). Nonetheless, the maximum water depths and velocities are slightly diffused with the latter meshes. The results obtained with the meshes S1M4 and A1M4 are clearly very diffusive and are not able to capture the maximum values of the water depth and velocity, although the general flow pattern can still be identified. Therefore, we have decided to work with the mesh S1M2 in the sinusoidal mould and A1M2 in the agricultural mould, which have a spatial resolution of $5 \mathrm{~mm}$ and $4 \mathrm{~mm}$ respectively. These meshes show a good compromise between computation time and accuracy on model output (Table 3). Results obtained with the finest meshes (S1M1 and A1M1) do not show significant differences while the computation time increases considerably. 


\subsection{Keulegan formulation applied to the sinusoidal mould}

The surface of the sinusoidal mould is made of sand grains with a diameter within 0.5 and $1.0 \mathrm{~mm}$. In non-cohesive beds without bedforms, river hydraulics manuals recommend to use a roughness height within 1 and 3 times the diameter of the sediment (Garcia, 2006). Based on this approximation, we have used a roughness height of $k_{s}=1.5 \mathrm{~mm}$ in the simulations of the sinusoidal mould test cases. It should be noticed that this approximation is recommended for river flows and not specifically for overland flows, where the water depth in some regions might be of the same order of magnitude as the roughness height. Nonetheless, as it will be shown in the following this bed roughness coefficient gives very satisfactory results in the four sinusoidal mould test cases.

Using Keulegan formulation with $k_{s}=1.5 \mathrm{~mm}$ the overall experimentalnumerical agreement is very satisfactory (Figures 5-11). The model predicts correctly the number of furrows which contribute to drain the inlet discharge (3 furrows in test cases $\mathrm{S} 1$ and $\mathrm{S} 2$, two furrows in test case $\mathrm{S} 3$, and one single furrow in test case S4). The prediction of the water depth field is very good in the four test cases. The root mean square errors on the water depth are $0.6 \mathrm{~mm}, 0.7 \mathrm{~mm}$, $0.7 \mathrm{~mm}$ and $0.9 \mathrm{~mm}$ for the test cases $\mathrm{S} 1$ to $\mathrm{S} 4$ respectively (Table 4), which are of the same order of magnitude as the diameter of the sediment which covers the mould surface. In all test cases the error on the water depth is less than $1 \mathrm{~mm}$ in more than $90 \%$ of the measurement points, while it is greater than $2 \mathrm{~mm}$ in less than $1 \%$ of the points (Figure 9). The accuracy on the prediction of the hydraulic jump which appears in the test cases $\mathrm{S} 1$ and $\mathrm{S} 4$ at the location $y=0.78 \mathrm{~m}$ in the profile $x=0.8 \mathrm{~m}$ is remarkable (Figure 11).

The comparison of the measured and computed velocities has a larger un- 
certainty for two reasons. Firstly, the LSPIV technique gives abnormally small velocities in regions where the water depth is very small, because the tracers occasionally rest attached to the rough bed surface. This occurs typically at the flow inlet and in the crests between furrows. In order to compare the velocities only the points in which the unit discharge is larger than $0.5 \mathrm{~cm}^{2} / \mathrm{s}$ were considered. This value was adopted because it defines rather precisely the shape of the furrows (Figures 5-8), and it excludes the regions where the LSPIV velocity has large measurement errors. Another source of uncertainty in the comparison of velocity data is the fact that LSPIV measures the surface velocity, while the numerical model computes the depth-averaged velocity. In order to estimate the surface velocity from the model output, the ratios mentioned in Legout et al. (2012) and in section 3.2 were adopted. With these criteria, the root mean square errors on the velocity are $0.089 \mathrm{~m} / \mathrm{s}, 0.058 \mathrm{~m} / \mathrm{s}, 0.083 \mathrm{~m} / \mathrm{s}$ and $0.065 \mathrm{~m} / \mathrm{s}$ respectively for the test cases S1 to S4 (Figure 10).

It should be noted that in the test case S1 (Figure 5), there is a clear disagreement between numerical predictions and experimental data in the third furrow, which is the one with the smallest water depth. The experimental measurements of water depth and velocity reveal a region between $x=0.1 \mathrm{~m}$ and $x=0.4 \mathrm{~m}$ where the flow is locally accelerated (higher velocity and lower water depth). The same effect appears in the test case S3 (Figure 7), but in this case in the second furrow (which is in this case the one which presents the smallest water depths). This local acceleration does not appear in the numerical model, as it can be observed in the velocity fields shown in Figures 5 and 8, and it is the reason why the root mean square error is larger in these test cases than in the cases S2 and S4. This discrepancy is represented in Figure 10 by the cloud of points in which 
the LSPIV velocity is clearly higher than the numerical velocity. We have tried unsuccessfully to improve the velocity predictions in these regions using different bed friction formulations (see section 4.3). We have not found a clear physical explanation for this effect.

\subsection{Other bed friction formulations applied to the sinusoidal mould}

The results shown in the previous section indicate that Keulegan formulation with a definition of the roughness height based on the physical properties of the mould surface (in our case the sediment diameter) performs satisfactorily in the sinusoidal mould. As roughness formulations are known to affect significantly the model performance (Mügler et al., 2011), we have explored the possibility of improving the predictions of the model by using other bed friction parameterizations. For that purpose we have considered the standard bed friction formulations shown in Table 1. Three of these formulations (Keulegan, Manning and Darcy with a constant friction factor) were developed for rough turbulent flow. The forth formulation is based on the formula of Colebrook-White, and considers the transitions between laminar flow, smooth turbulent flow and rough turbulent flow. In this latter formulation the laminar bed friction formula is used if the local Reynolds number is smaller than $2000(4 U h / \nu<2000)$, otherwise the Colebrook-White equation is applied. In all cases the bed roughness parameter was calibrated for the test case $\mathrm{S} 1$ and then used in the test cases S2, S3 and S4.

After calibration of their respective friction parameters, all the parameterizations give a similar agreement with the experimental data (Tables 4 and 4). Their performance considering the water depth and velocity spatial distributions is rather satisfactory, specially regarding the water depth. The agreement in the velocity field is slightly better when using Keulegan or Manning formulations, 
although the performance of Darcy and Colebrook-White formulations is still acceptable. The main advantage of Keulegan parameterization is that the roughness height is more easily related to the roughness characteristics of the terrain than the Manning or Darcy coefficients.

\subsection{Agricultural mould}

The most significant difference between the sinusoidal and the agricultural moulds is that the latter one includes soil aggregates which create a certain level of macro-roughness. As shown in Figure 2, the size and location of the soil aggregates is well captured by the numerical meshes with a spatial resolution of $2 \mathrm{~mm}$ and $4 \mathrm{~mm}$ (A1M1 and A1M2), but they are reduced as the grid resolution is reduced. The macro-roughness generated by these soil aggregates induces small scale accelerations and decelerations in the flow field, causing additional head losses. One of the purposes of the agricultural terrain test cases is to analyze if a high resolution shallow water model with a micro-roughness coefficient defined from the bed material (in this case plaster) is able to reproduce the experimental velocity field.

Test case A1 has been used for model calibration and to analyze how the bed friction coefficient should be modified in order to account for the macroroughness. Test case A2 has been used for model validation, using the same roughness parameterization as in case A1.

Figure 12 shows that the velocity field computed using a bed roughness coefficient for plaster (either $k_{s}=1 \mathrm{~mm}$ in Keulegan formulation or $n=0.013 \mathrm{~s} \mathrm{~m}^{-1 / 3}$ in Manning formulation) are far from the experimental ones, even if the computations were done with a high resolution mesh which includes all the small scale details of the topography. The computed velocities are too large compared 
with the LSPIV measurements. The root mean square error obtained with Keulegan and Manning formulas using these parameters are respectively $0.095 \mathrm{~m} / \mathrm{s}$ and $0.100 \mathrm{~m} / \mathrm{s}$ (Table 5).

Model outputs is improved significantly if a larger bed friction coefficient is used. After calibration, the coefficients which produce the best numericalexperimental agreement were found to be $k_{s}=30 \mathrm{~mm}$ and $n=0.050 \mathrm{~s} \mathrm{~m}^{-1 / 3}$, the root mean square error for the velocity being $0.040 \mathrm{~m} / \mathrm{s}$ for both cases. The velocity fields computed with these parameters show a good global agreement with the LSPIV data (Figure 12). Both, experimental and numerical results show a shallow and narrow arm which develops to the left of the upper furrow and joins the lower furrow further downstream.

It can be noticed in Figure 12 that the numerical model gives some locally high velocity values which do not appear in the experimental data. These local velocity peaks are due to the highly irregular topography created by the soil aggregates. The energy losses induced by these high frequency accelerations are not well represented by the shallow water equations with the standard bed friction formulations, even if a very detailed grid and DTM are used in the computations. This explains the high value of the bed friction coefficient found in the calibration $\left(k_{s}=30 \mathrm{~mm}\right.$ and $\left.n=0.050 \mathrm{~s} \mathrm{~m}^{-1 / 3}\right)$.

The roughness coefficient in Keulegan formulation might be related to the macro-roughness of the bed surface. For this purpose, the roughness height in Keulegan formulation was defined on a physical basis as $k_{s}=A l_{\Delta}$, where $l_{\Delta}$ is a local measure of the macro-roughness length scale, and $A$ is a constant of order 1. The level of macro-roughness in the agricultural mould is not homogeneous, the spatial density and size of the soil aggregates in the upper furrow being lower 
than in the lower furrow. Therefore, a spatially variable macro-roughness length scale $l_{\Delta}$ was defined from the residuals $(\Delta z)$ obtained after filtering the original DTM with an average filter of size $\Delta$. After trying several definitions of $l_{\Delta}$ and filter sizes, a suitable definition for the roughness height was obtained with $A=1$, and $l_{\Delta}=\max (\Delta z)$, where the residuals $\Delta z$ are computed using an average filter of size $\Delta=10 \mathrm{~mm}$. The velocity results obtained using this macro-roughness based definition for the roughness height $\left(k_{s}=\max (\Delta z)\right)$ are shown in Figure 12. There is not a significant improvement relative to the results obtained with a constant roughness coefficient $\left(k_{s}=30 \mathrm{~mm}\right)$, but in this case the values of $k_{s}$ vary locally according to the physical characteristics of the macro-roughness, as shown in Figure 13.

The same roughness parameterizations applied to the test case A2 gives satisfactory results (Figure 13). Although the quantitative agreement between numerical and experimental data is not as good as in test case A1 (Table 5), the differences are of the same order as the uncertainty on the experimental surface velocity (section 3.2). This increase in the root mean square error is to some extent explained by the gaps in the experimental velocity data which can be observed in Figure 13. Due to the extremely low water depths and the high surface roughness of the agricultural mould, there are some isolated spots in which tracers could not move and thus velocity was not correctly measured. This introduces spurious disagreements with the numerical model which are reflected in the root mean square error. Nonetheless, visual comparison of the velocity fields in Figure 13 shows a similar global agreement to that of test case A1. 


\section{CONCLUSIONS}

The performance of an overland flow model based on the two-dimensional shallow water equations has been analyzed using high-resolution distributed measurements of water depth and velocity. Several flow conditions over two impervious moulds with different micro and macro-roughness characteristics have been used for model validation.

The flow in the sinusoidal mould, which represents a terrain with a regular topography and no macro-roughness, is properly represented by the two-dimensional shallow water equations with a constant bed friction coefficient. This latter can be related to the micro-roughness characteristics of the bed surface. Manning and Keulegan formulations produce results with similar accuracy. More complex formulations which consider the transitions between laminar, smooth turbulent and rough turbulent flow conditions, do not improve model performance.

In terrains with a certain level of macro-roughness, as it is the case of the agricultural mould with soil aggregates, the two-dimensional shallow water equations with a bed friction coefficient defined from the micro-roughness of the bed surface are not able to accurately reproduce the flow field. This is because the soil aggregates which define the macro-roughness produce small scale accelerations and decelerations in the flow field, which generate additional head losses. Even if the mesh size is smaller than the soil aggregates, these head losses cannot be captured by the model equations. In order to correctly reproduce the flow hydrodynamic, the bed roughness coefficient must account for the macro-roughness of the terrain generated by the presence of soil aggregates.

In the agricultural mould the bed roughness height used in Keulegan formulation $\left(k_{s}\right)$ could be related to the local macro-roughness length scale of the bed 
surface $\left(l_{\Delta}\right)$ by the simple relation $\left(k_{s}=l_{\Delta}\right)$. In the test cases analyzed in this work a proper definition of $l_{\Delta}$ is the maximum residual obtained after filtering the original DTM with a filter size of $10 \mathrm{~mm}$, and it is related to the size of the soil aggregates. The problem with this approach when applied to larger scales is that a very fine spatial resolution is required in order to apply a $10 \mathrm{~mm}$ filter to the DTM, which limits the applicability of a macro-roughness based definition of $k_{s}$. These results show that using a physically-based definition of the bed roughness coefficient, a two-dimensional shallow water model is able to reproduce the velocity and water depth patterns under runoff conditions. In the test cases analyzed in this paper the average errors on the water depth and velocity were $0.7 \mathrm{~mm}$ and $0.07 \mathrm{~m} / \mathrm{s}$ respectively. This justifies the use of the shallow water equations in physically-based erosion and solute transport models that require a very detailed spatial characterization of the flow field in order to take advantage of their full potential. Regarding the applicability of the model to larger scales, and thus more relevant for hillslope hydrology understanding, the limiting factor is the DEM and mesh resolution required for the computations. A spatial resolution of the order of $10 \mathrm{~mm}$ is required to capture the flow patterns and the range of depth and velocity values. Applying such a high resolution shallow water model to plot scales of a few hundreds of square meters would lead to reasonable computation times (of the order of $5 \mathrm{~h}$ in a standard laptop for a $100 \mathrm{~m}^{2}$ plot). Such resolution is also consistent with what can be obtained from stereophotogrammetry or laser scanner techniques in field conditions. 


\section{References}

Abrahams, A.D., Li, G., Krishnan, C., Atkinson, J.F., 1998. Predicting sediment transport by interril overland flow on rough surfaces. Earth Surf. Process. Landforms 23, 1087-1099.

Cea, L., Garrido, M., Puertas, J., 2010a. Experimental validation of twodimensional depth-averaged models for forecasting rainfall-runoff from precipitation data in urban areas. Journal of Hydrology 382, 88-102.

Cea, L., Garrido, M., Puertas, J., Jácome, A., del Río, H., Suárez, J., 2010b. Overland flow computations in urban and industrial catchments from direct precipitation data using a two-dimensional shallow water model. Water Science and Technology 62, 1998-2008.

Cea, L., Vázquez-Cendón, M.E., 2012. Unstructured finite volume discretization of bed friction and convective flux in solute transport models linked to the shallow water equations. Journal of Computational Physics 231, 3317-3339.

Fraga, I., Cea, L., Puertas, J., 2013. Experimental study of the water depth and rainfall intensity effects on the bed roughness coefficient used in distributed urban drainage models. Journal of Hydrology 505, 266-275.

Darboux, F., Huang, C., 2003. An instantaneous-profile laser scanner to measure soil surface microtopography. Soil Sci. Soc. Am. J. 67, 92-99.

Garcia, M.H., 2006. Sedimentation Engineering: Processes, Measurements, Modeling, and Practice. ASCE, Reston, Virginia. 
Hairsine, P.B., Rose, C.W., 1992a. Modeling water erosion due to overland-flow using physical principles. 1. rill flow. Water Resources Research 28, 245-250.

Hairsine, P.B., Rose, C.W., 1992b. Modeling water erosion due to overland-flow using physical principles. 1. sheet flow. Water Resources Research 28, 237243.

Howes, D.A., Abrahams, A.D., Pitman, E.B., 2006. One- and two-dimensional modelling of overland flow in semiarid shrubland, jornada basin, new mexico. Hydrol. Process. 20, 1027-1046.

Jarvela, J., 2002. Flow resistance of flexible and stiff vegetation: a flume study with natural plants. Journal of Hydrology 269, 44-54.

Jomaa, S., Barry, D.A., Brovelli, A., Sander, G.C., Parlange, J.Y., Heng, B.C.P., van Meerveld, H.J.T., 2010. Effect of raindrop splash and transversal width on soil erosion: Laboratory flume experiments and analysis with the HairsineÛRose model. Journal of Hydrology 395, 117-132.

Kamphorst, E.C., Duval, Y., 2001. Validation of a numerical method to quantify depression storage by direct measurements on moulded surfaces. CATENA 43, $1-14$.

Kivva, S.L., Zheleznyak, M.J., 2005. Two-dimensional modeling of rainfall runoff and sediment transport in small catchments areas. International Journal of Fluid Mechanics Research 32, 703-716.

Lawrence, D.S.L., 2000. Hydraulic resistance in overland flow during partial and marginal surface inundation: Experimental observations and modeling. Water Resources Research 36, 2381-2393. 
Legout, C., Darboux, F., Nedelec, Y., Hauet, A., Esteves, M., Renaux, B., Denis, H., Cordier, S., 2012. High spatial resolution mapping of surface velocities and depths for shallow overland flow. Earth Surface Processes and Landforms 37, 984-993.

LeVeque, R.J., 2002. Finite Volume Methods for Hyperbolic Problems. volume 31 of Cambridge Texts in Applied Mathematics. Cambridge University Press.

Mügler, C., Planchon, O., Patin, J., Weill, S., Silvera, N., Richard, P., Mouche, E., 2011. Comparison of roughness models to simulate overland flow and tracer transport experiments under simulated rainfall at plot scale. Journal of Hydrology 402, 25-40.

Morgali, J.R., Linsley, R.K., 1965. Computer analysis of overland flow. Journal of the Hydraulics Division. Proceedings of the American Society of Civil Engineers HY3, 81-100.

Nord, G., Esteves, M., 2007. Evaluation of sediment transport formulae and detachment parameters in eroding rills using PSEM2D and the Water Erosion Prediction Project (WEPP) database. Water Resources Research 43, 1-14.

Nord, G., Esteves, M., 2010. The effect of soil type, meteorological forcing and slope gradient on the simulation of internal erosion processes at the local scale. Hydrological Processes 24, 1766-1780.

Shaw, S.B., Parlange, J.Y., Lebowitz, M., Walter, M.T., 2009. Accounting for surface roughness in a physically-based urban wash-off model. Journal of Hydrology 367, 79-85. 
Table 1: Bed friction formulations considered in the numerical simulations. $f$ : Darcy's friction factor; $k_{s}$ : roughness height; $n$ : Manning coefficient; $\nu$ : kinematic viscosity of water $\left(10^{-6} \mathrm{~m}^{2} / \mathrm{s}\right)$.

$\begin{array}{ll}\text { Formulation } & \text { Friction factor parameterization } \\ \text { Darcy }(f) & C_{f}=\frac{f}{8} \\ \text { Keulegan }\left(k_{s}\right) & C_{f}=0.16\left(\ln 11 h / k_{s}\right)^{-2} \\ \text { Manning }(n) & C_{f}=g \frac{n^{2}}{h^{1 / 3}} \\ \text { Colebrook-White }\left(k_{s}\right) & C_{f}=0.16\left(-\ln \left(\frac{k_{s}}{11 h}+\frac{2.5 \nu}{11.9 U h \sqrt{C_{f}}}\right)\right)^{-2} \\ \text { Laminar } & C_{f}=\frac{3 \nu}{|\mathbf{U}| h}\end{array}$

477

Shaw, S.B., Walter, M.T., Steenhuis, T.S., 2006. A physical model of particulate wash-off from rough impervious surfaces. Journal of Hydrology 327, 618-626.

Tatard, L., Planchon, O., Wainwright, J., Nord, G., Favis-Mortlock, D., Silvera, N., Ribolzi, O., Esteves, M., Huang, C.H., 2008. Measurement and modelling of high-resolution flow-velocity data under simulated rainfall on a low-slope sandy soil. Journal of Hydrology 348, 1 - 12.

Toro, E.F., 2001. Shock-capturing Methods for Free-Surface Shallow Flows. Wiley, Chichester, West Sussex PO19 1UD, England.

Yan, M., Kahawita, R., 1989. Simulating the evolution of non-point source pollutants in a shallow water environment. Chemosphere 67, 879-885.

Zhang, Cundy, 1989. Modeling of two-dimensional overland flow. Water Resources Research 25, 2019-2035. 
Table 2: Summary of experimental test cases used for model validation.

$\begin{array}{lccccc}\text { Test case } & \text { Mould } & \text { Surface } & \text { Flow rate }\left(\mathrm{cm}^{3} / \mathrm{s}\right) & \text { Slope Y-dir }(\%) & \text { Slope X-dir (\%) } \\ \text { S1 } & \text { sinusoidal } & \text { Sand } & 110 & 20.4 & 3.2 \\ \text { S2 } & \text { sinusoidal } & \text { Sand } & 131 & 18.1 & 0.0 \\ \text { S3 } & \text { sinusoidal } & \text { Sand } & 79 & 18.0 & 3.1 \\ \text { S4 } & \text { sinusoidal } & \text { Sand } & 93 & 14.4 & 11.4 \\ \text { A1 } & \text { agricultural } & \text { Plaster } & 182 & 0.0 & 4.0 \\ \text { A2 } & \text { agricultural } & \text { Plaster } & 177 & 0.0 & 7.7\end{array}$

Table 3: Mesh convergence analysis for the sinusoidal and agricultural moulds. The results obtained with meshes S1M1 and A1M1 are used as a reference to compute the root mean square error in water depth $\left(\sigma_{h}\right)$ and velocity $\left(\sigma_{v}\right)$ on the coarser meshes. $\Delta x$ is the mesh size, $N_{\text {nod }}$ is the number of elements in the mesh, and $T_{c}$ is the computation time with an Intel Core i7 - 1.60 $\mathrm{GHz}$.

$\begin{array}{lcccccc}\text { Test case } & \text { Mesh } & \Delta x & N_{\text {nod }} & T_{c} & \sigma_{h} & \sigma_{v} \\ \text { S1 } & \text { S1M1 } & 2 \mathrm{~mm} & 170817 & 5400 \mathrm{~s} & - & - \\ \text { S1 } & \text { S1M2 } & 5 \mathrm{~mm} & 38971 & 340 \mathrm{~s} & 0.17 \mathrm{~mm} & 0.018 \mathrm{~m} / \mathrm{s} \\ \text { S1 } & \text { S1M3 } & 10 \mathrm{~mm} & 9748 & 35 \mathrm{~s} & 0.28 \mathrm{~mm} & 0.034 \mathrm{~m} / \mathrm{s} \\ \text { S1 } & \text { S1M4 } & 20 \mathrm{~mm} & 2467 & 4 \mathrm{~s} & 0.67 \mathrm{~mm} & 0.065 \mathrm{~m} / \mathrm{s} \\ \text { A1 } & \text { A1M1 } & 2 \mathrm{~mm} & 115840 & 4200 \mathrm{~s} & - & - \\ \text { A1 } & \text { A1M2 } & 4 \mathrm{~mm} & 28960 & 600 \mathrm{~s} & - & 0.013 \mathrm{~m} / \mathrm{s} \\ \text { A1 } & \text { A1M3 } & 8 \mathrm{~mm} & 6400 & 60 \mathrm{~s} & - & 0.031 \mathrm{~m} / \mathrm{s} \\ \text { A1 } & \text { A1M4 } & 16 \mathrm{~mm} & 1600 & 8 \mathrm{~s} & - & 0.265 \mathrm{~m} / \mathrm{s}\end{array}$


Table 4: Performance of different bed friction parameterizations in the test cases S1, S2, S3 and $\mathrm{S} 4$, evaluated as the root mean square error of the water depth $\left(\sigma_{h}\right)$ and velocity $\left(\sigma_{v}\right)$.

\begin{tabular}{lccccccccc}
\multicolumn{1}{c}{ Parameterization } & \multicolumn{4}{c}{$\sigma_{h}(\mathrm{~mm})$} & \multicolumn{6}{c}{$\sigma_{v}(\mathrm{~m} / \mathrm{s})$} \\
& $\mathrm{S} 1$ & $\mathrm{~S} 2$ & $\mathrm{~S} 3$ & $\mathrm{~S} 4$ & $\mathrm{~S} 1$ & $\mathrm{~S} 2$ & $\mathrm{~S} 3$ & $\mathrm{~S} 4$ \\
Keulegan $\left(k_{s}=1.5 \mathrm{~mm}\right)$ & 0.6 & 0.7 & 0.7 & 0.9 & 0.089 & 0.058 & 0.083 & 0.065 \\
Manning $\left(n=0.015 \mathrm{~s} \mathrm{~m}^{-1 / 3}\right)$ & 0.6 & 0.7 & 0.6 & 0.9 & 0.094 & 0.070 & 0.084 & 0.068 \\
Darcy $(f=0.16)$ & 0.6 & 0.8 & 0.8 & 1.1 & 0.099 & 0.063 & 0.088 & 0.100 \\
Colebrook-White $\left(k_{s}=1.5 \mathrm{~mm}\right)$ & 0.8 & 0.7 & 0.6 & 1.0 & 0.098 & 0.067 & 0.090 & 0.110
\end{tabular}

Table 5: Performance of different bed friction parameterizations in the test cases A1 and A2 in the agricultural mould, evaluated as the root mean square error of the velocity.

$\begin{array}{llcc}\text { Parameterization } & \text { Friction factor } & \text { A1 } & \text { A2 } \\ \text { Keulegan } & k_{s}=1 \mathrm{~mm} & 0.095 \mathrm{~m} / \mathrm{s} & 0.140 \mathrm{~m} / \mathrm{s} \\ \text { Keulegan } & k_{s}=30 \mathrm{~mm} & 0.040 \mathrm{~m} / \mathrm{s} & 0.062 \mathrm{~m} / \mathrm{s} \\ \text { Manning } & n=0.013 \mathrm{~s} \mathrm{~m}^{-1 / 3} & 0.100 \mathrm{~m} / \mathrm{s} & 0.150 \mathrm{~m} / \mathrm{s} \\ \text { Manning } & n=0.050 \mathrm{~s} \mathrm{~m}^{-1 / 3} & 0.040 \mathrm{~m} / \mathrm{s} & 0.071 \mathrm{~m} / \mathrm{s} \\ \text { Keulegan } & k_{s}=\max \Delta_{z} & 0.039 \mathrm{~m} / \mathrm{s} & 0.062 \mathrm{~m} / \mathrm{s}\end{array}$




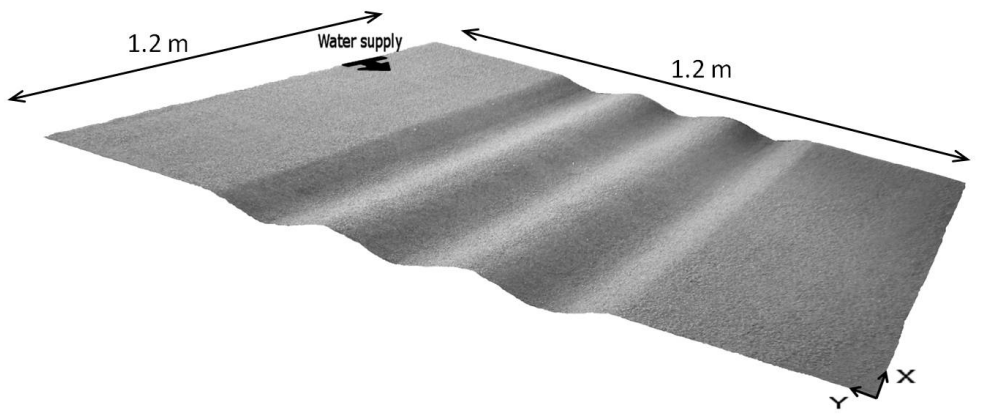

Figure 1: Representation of the sinusoidal mould. 


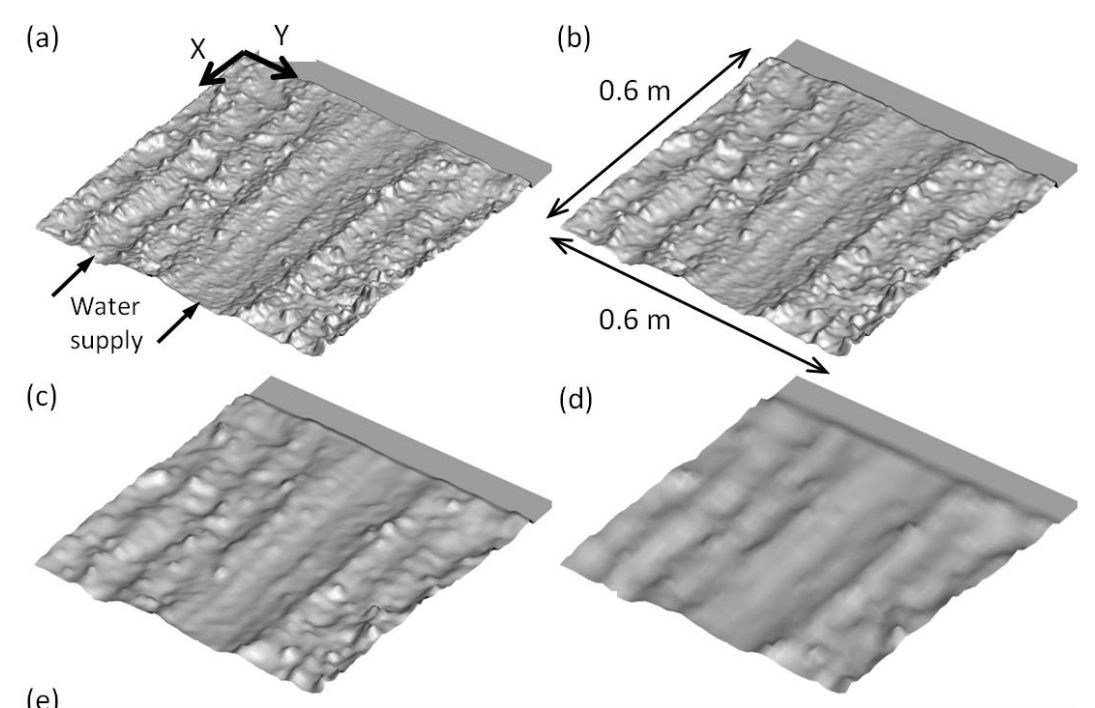

(e)

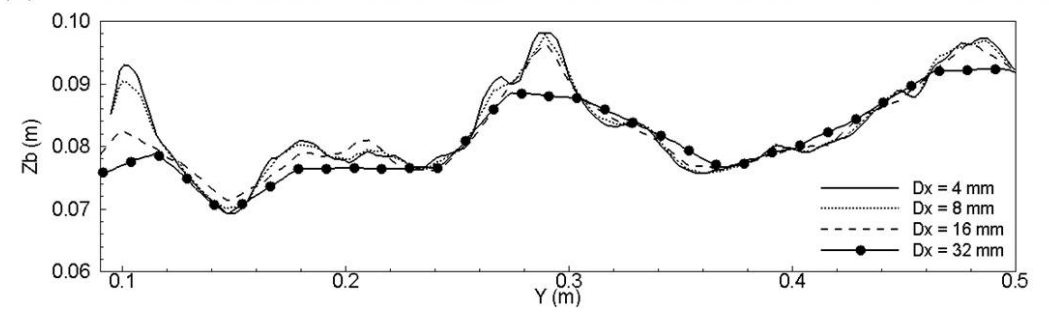

Figure 2: Representation of the agricultural seedbed mould after filtering the original DTM with several filter sizes ( $\Delta$ ). (a) Original DTM, (b) $\Delta=4 \mathrm{~mm}$, (c) $\Delta=8 \mathrm{~mm}$ (d) $\Delta=16 \mathrm{~mm}$, and (e) cross section at $x=0.3 \mathrm{~m}$ computed from the filtered DTM's. 

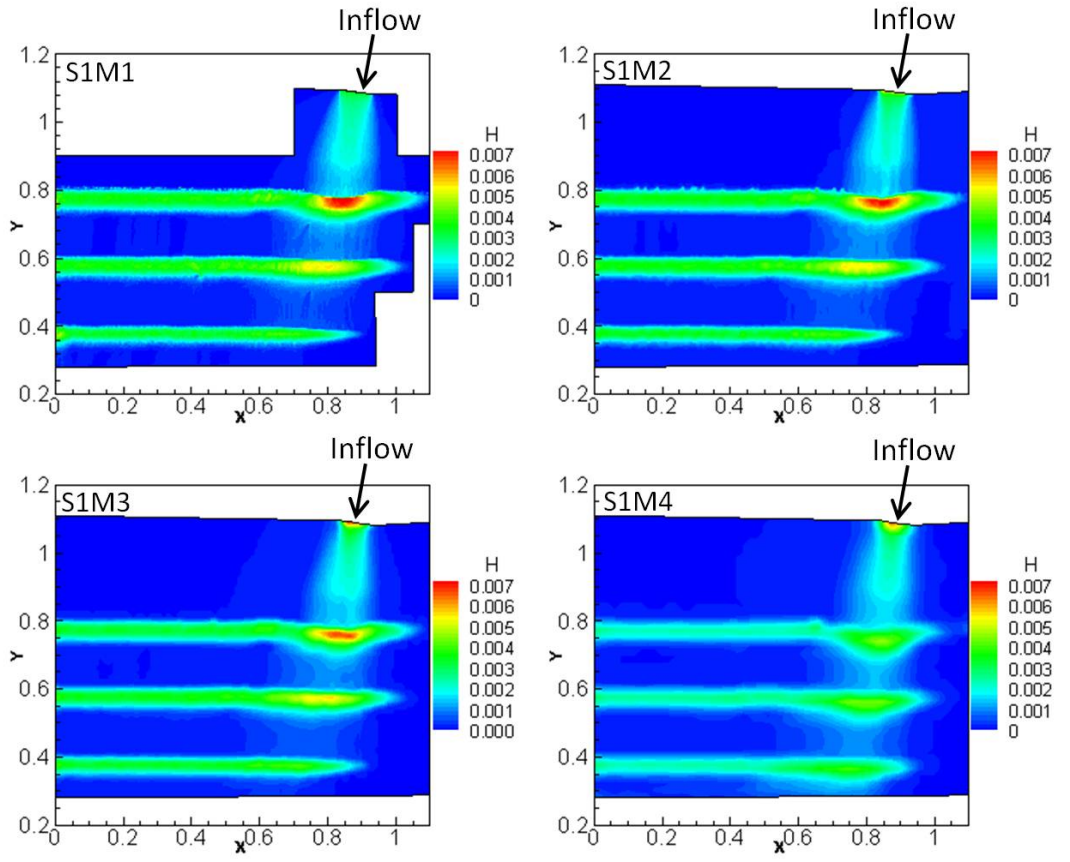

Figure 3: Mesh convergence in the sinusoidal mould. Water depth (m) computed with the meshes S1M1 (top-left), S1M2 (top-right), S1M3 (bottom-left) and S1M4 (bottom-right). Axes units in meters. 

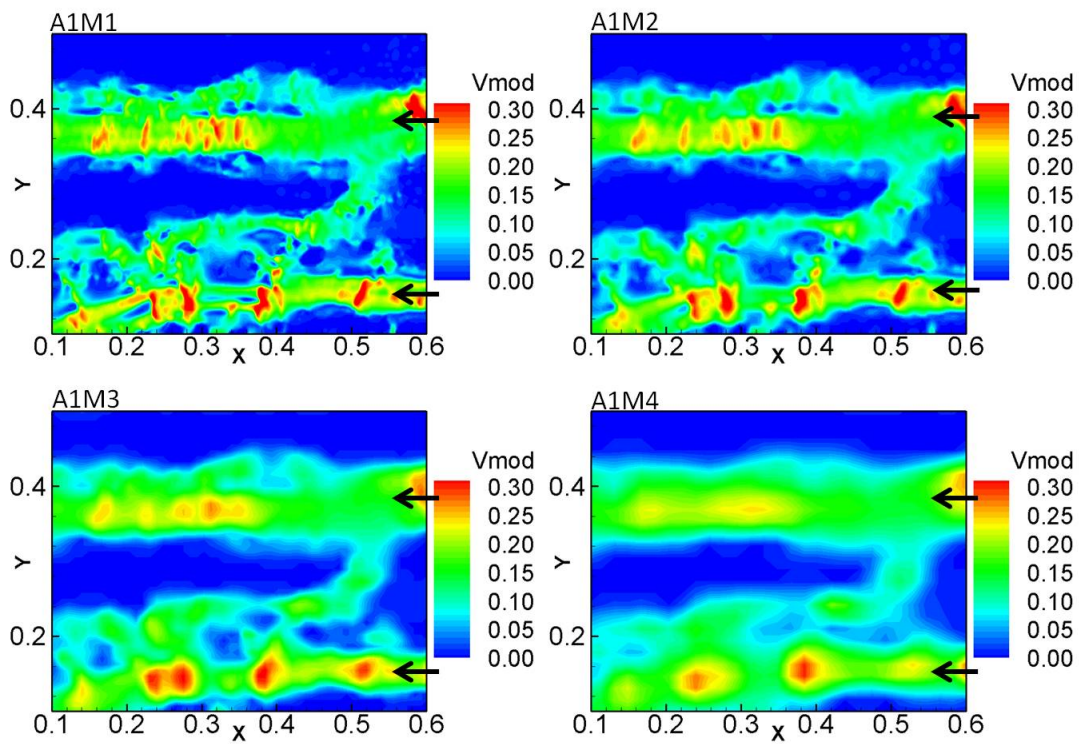

Figure 4: Mesh convergence in the agricultural mould. Black arrows indicate inflow locations. Velocity (m/s) computed with the meshes A1M1 (top-left), A1M2 (top-right), A1M3 (bottomleft) and A1M4 (bottom-right). Axes units in meters. 

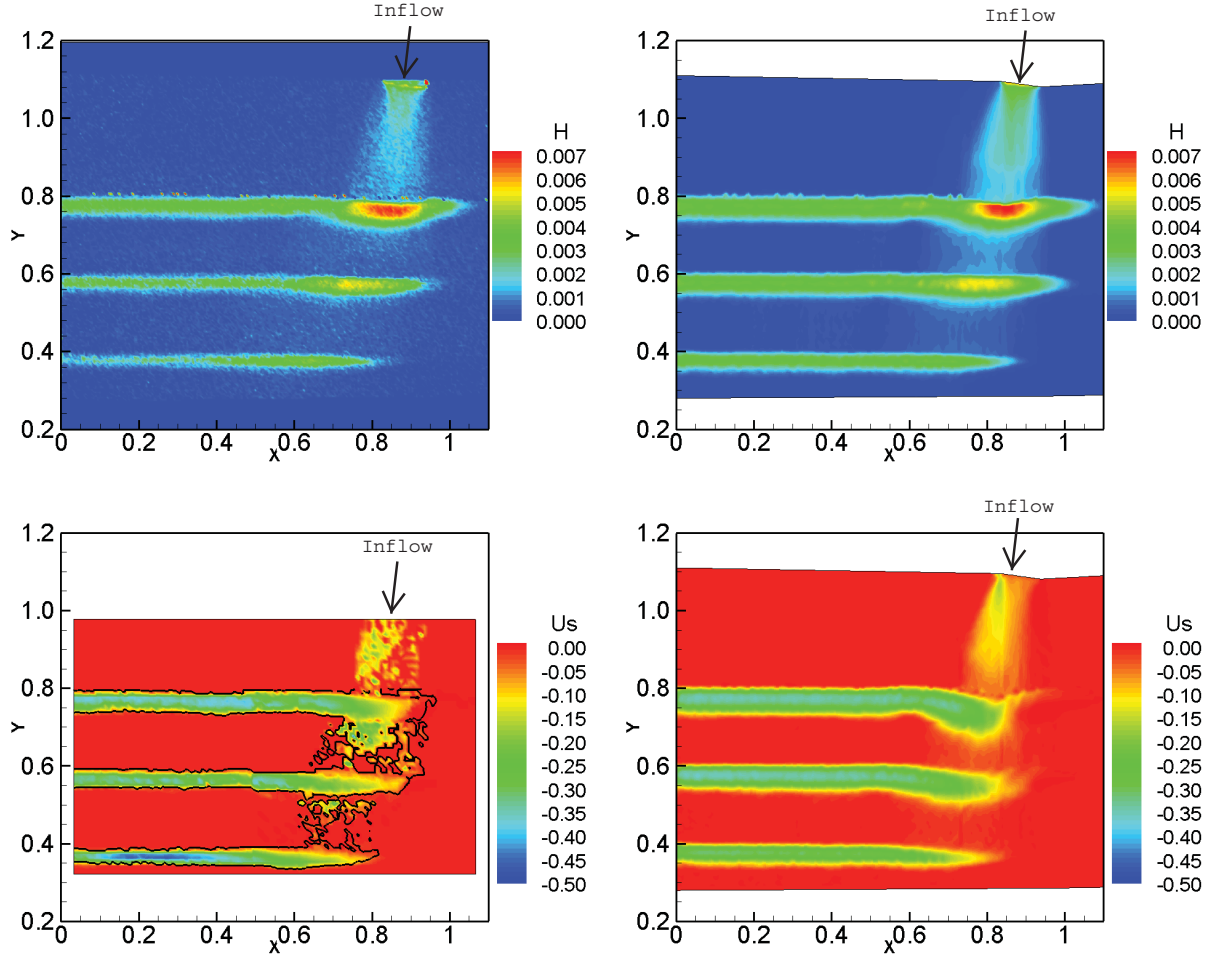

Figure 5: Experimental (left) and numerical (right) water depth $(\mathrm{m})$ and surface velocity $(\mathrm{m} / \mathrm{s})$ fields for the test case S1. Numerical results were obtained with Keulegan formulation and $k_{s}=$ $1.5 \mathrm{~mm}$. The black contour defines the region used to compute the root mean square error for the velocity (Table 4). Axes units in meters. 

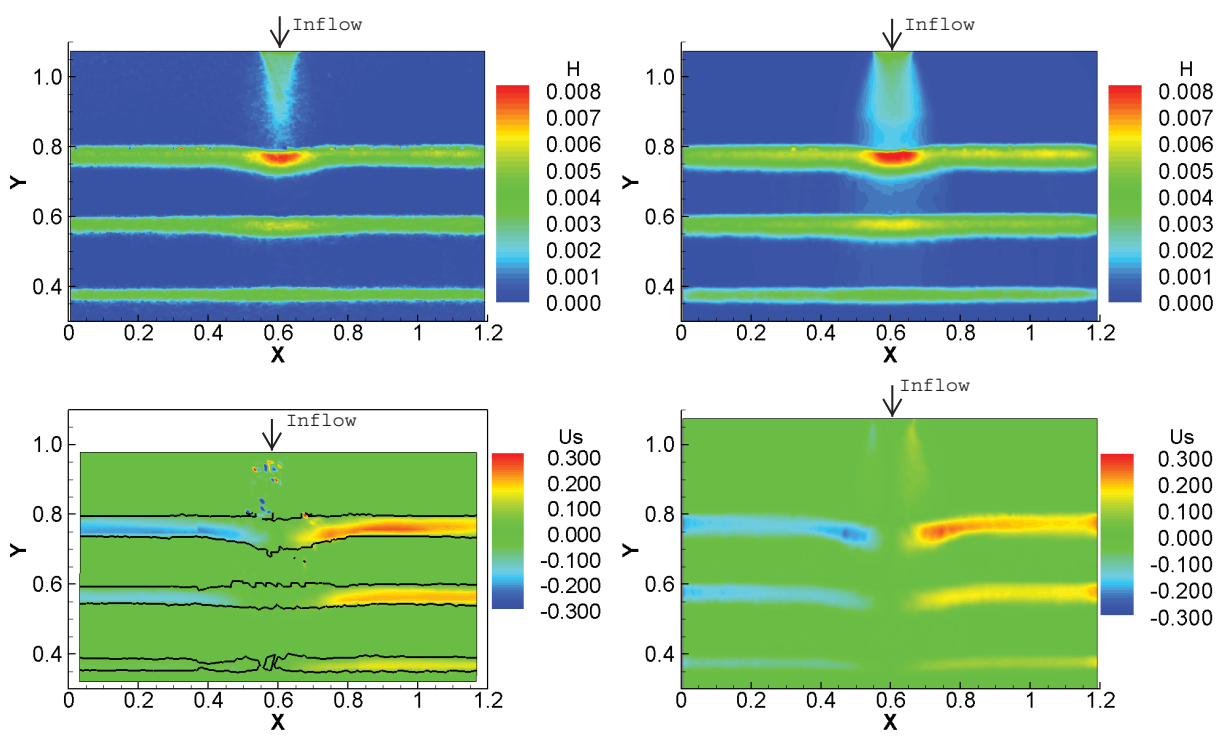

Figure 6: Experimental (left) and numerical (right) water depth $(\mathrm{m})$ and surface velocity $(\mathrm{m} / \mathrm{s})$ fields for the test case S2. Numerical results were obtained with Keulegan formulation and $k_{s}=$ $1.5 \mathrm{~mm}$. The black contour defines the region used to compute the root mean square error for the velocity (Table 4). Axes units in meters. 

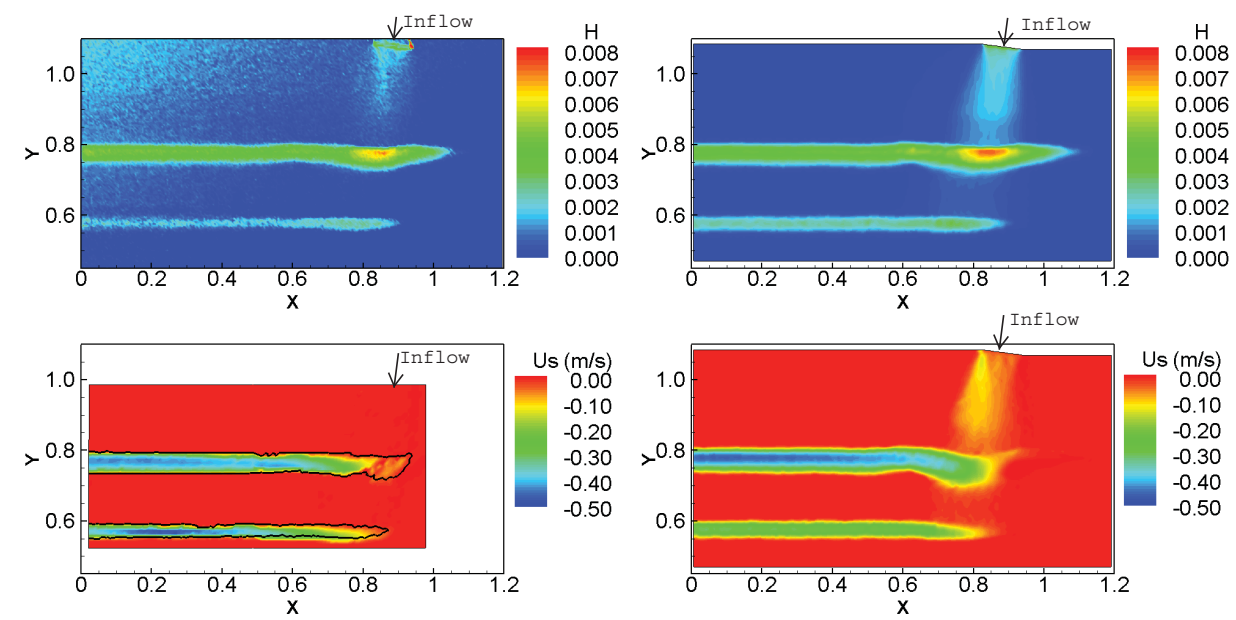

Figure 7: Experimental (left) and numerical (right) water depth $(\mathrm{m})$ and surface velocity $(\mathrm{m} / \mathrm{s})$ fields for the test case S3. Numerical results were obtained with Keulegan formulation and $k_{s}=$ $1.5 \mathrm{~mm}$. The black contour defines the region used to compute the root mean square error for the velocity (Table 4). Axes units in meters.
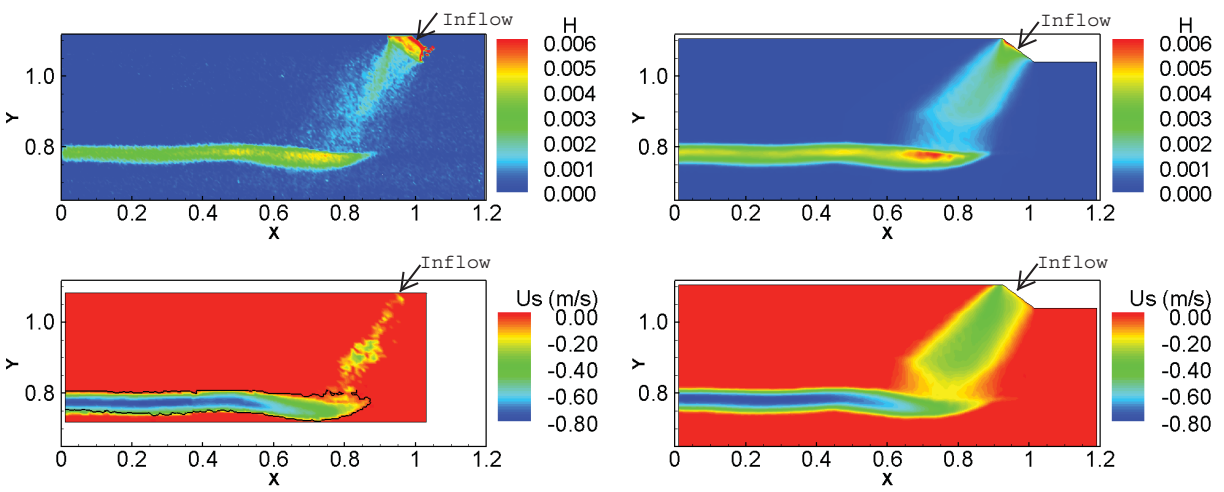

Figure 8: Experimental (left) and numerical (right) water depth $(\mathrm{m})$ and surface velocity $(\mathrm{m} / \mathrm{s})$ fields for the test case S4. Numerical results were obtained with Keulegan formulation and $k_{s}=$ $1.5 \mathrm{~mm}$. The black contour defines the region used to compute the root mean square error for the velocity (Table 4). Axes units in meters. 

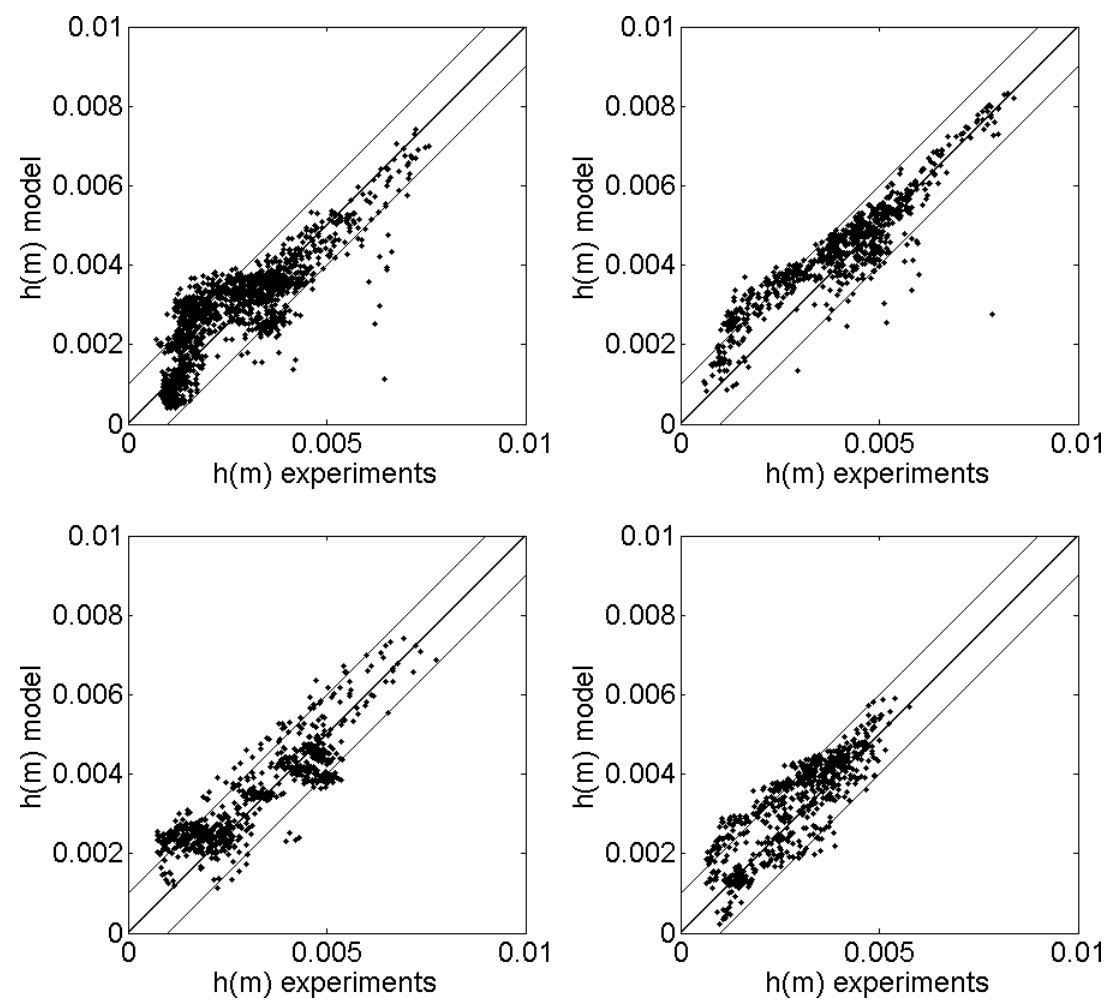

Figure 9: Computed vs. modelled water depths in the sinusoidal mould. Test cases S1 (topleft), S2 (top-right), S3 (bottom-left) and S4 (bottom-right). Lines above and below the 1:1 line correspond to the maximum experimental uncertainty of $1 \mathrm{~mm}$. 

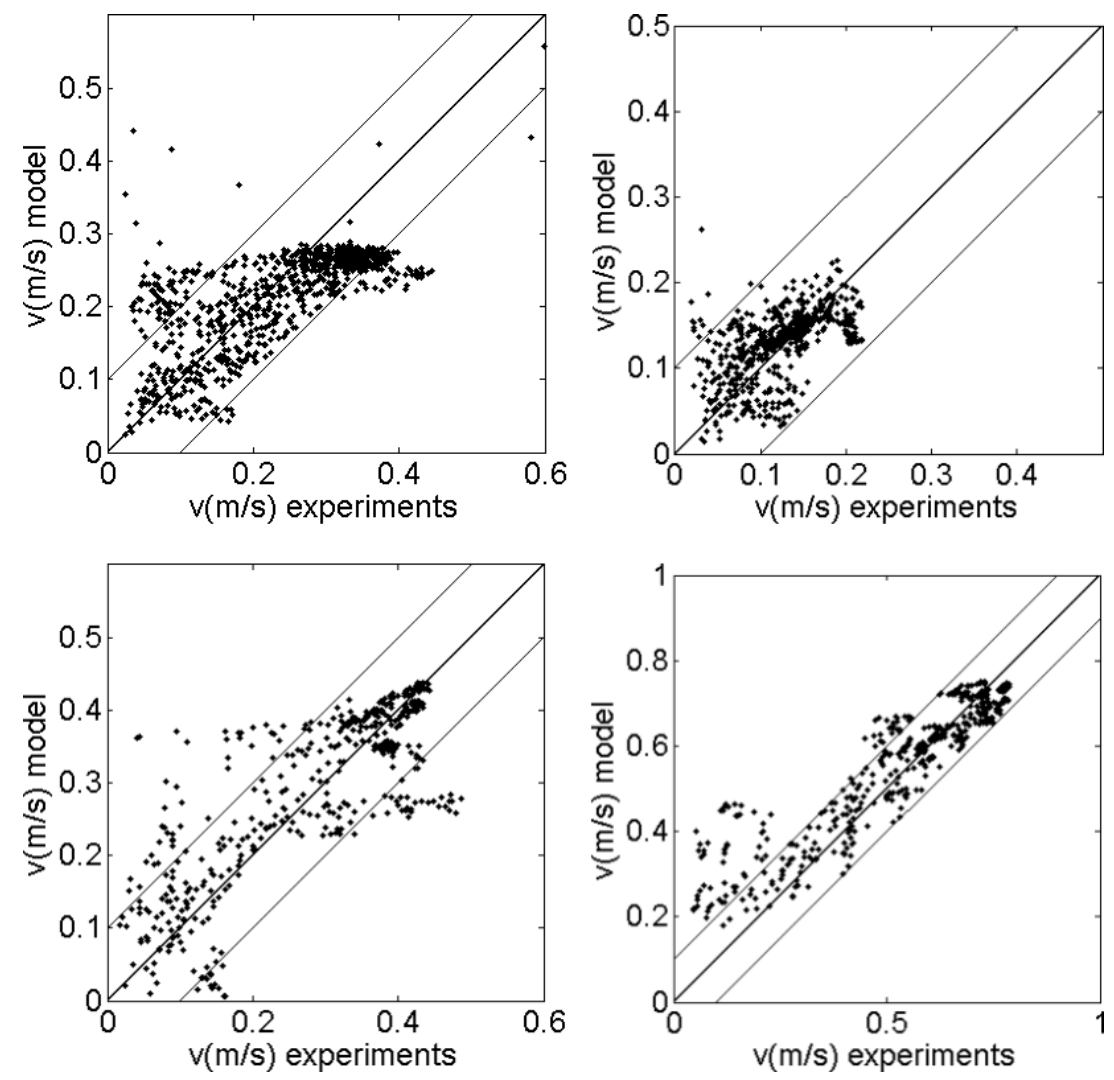

Figure 10: Computed vs. modelled velocities in the sinusoidal mould. Test cases S1 (top-left), S2 (top-right), S3 (bottom-left) and S4 (bottom-right). Lines above and below the 1:1 line correspond to the maximum experimental uncertainty of $0.10 \mathrm{~m} / \mathrm{s}$. 

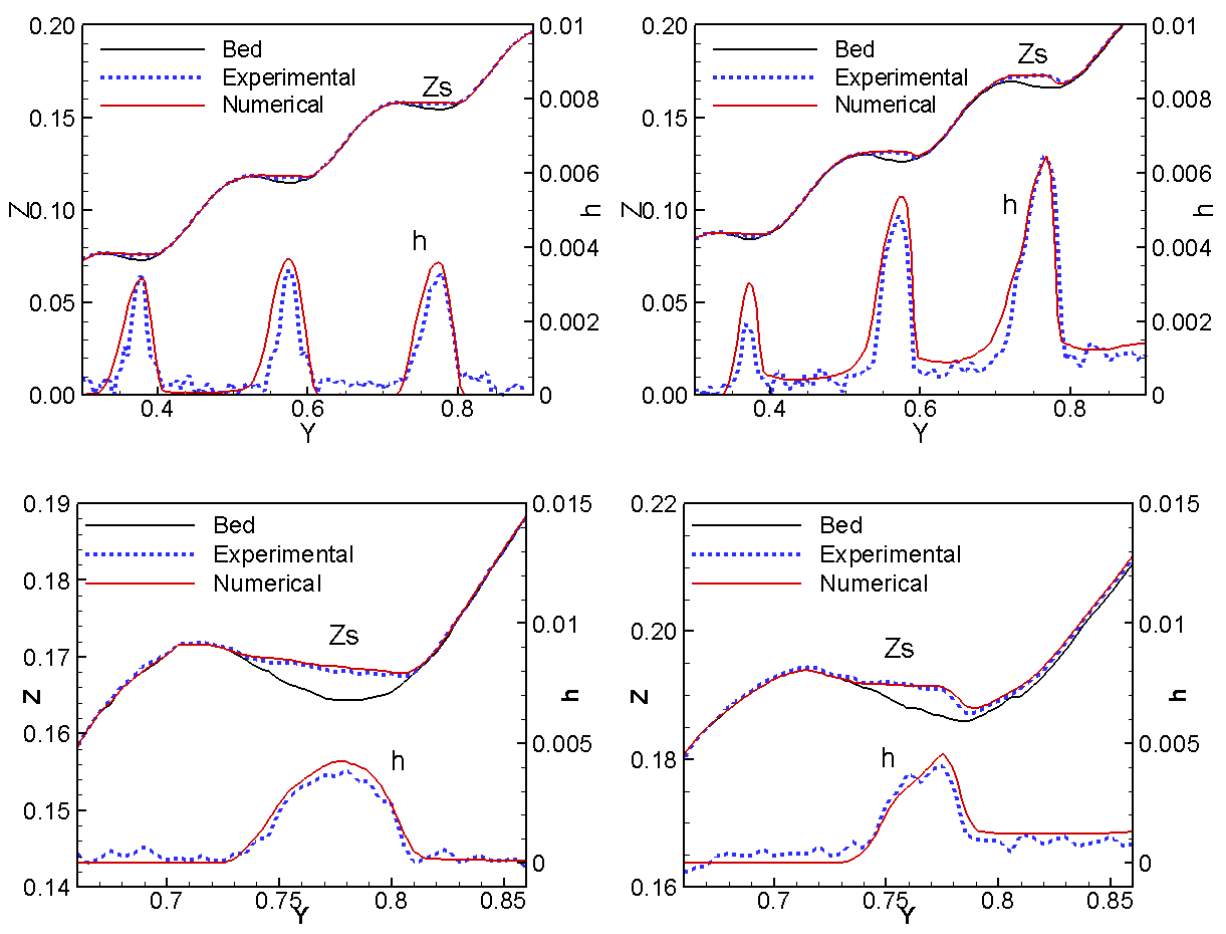

Figure 11: Experimental vs. numerical water depth (m) profiles in the sinusoidal mould. Test cases: $\mathrm{S} 1$ at $x=0.4 \mathrm{~m}$ (top-left), $\mathrm{S} 1$ at $x=0.8 \mathrm{~m}$ (top-right), $\mathrm{S} 4$ at $x=0.6 \mathrm{~m}$ (bottom-left) and $\mathrm{S} 4$ at $x=0.8 \mathrm{~m}$ (bottom-right). 

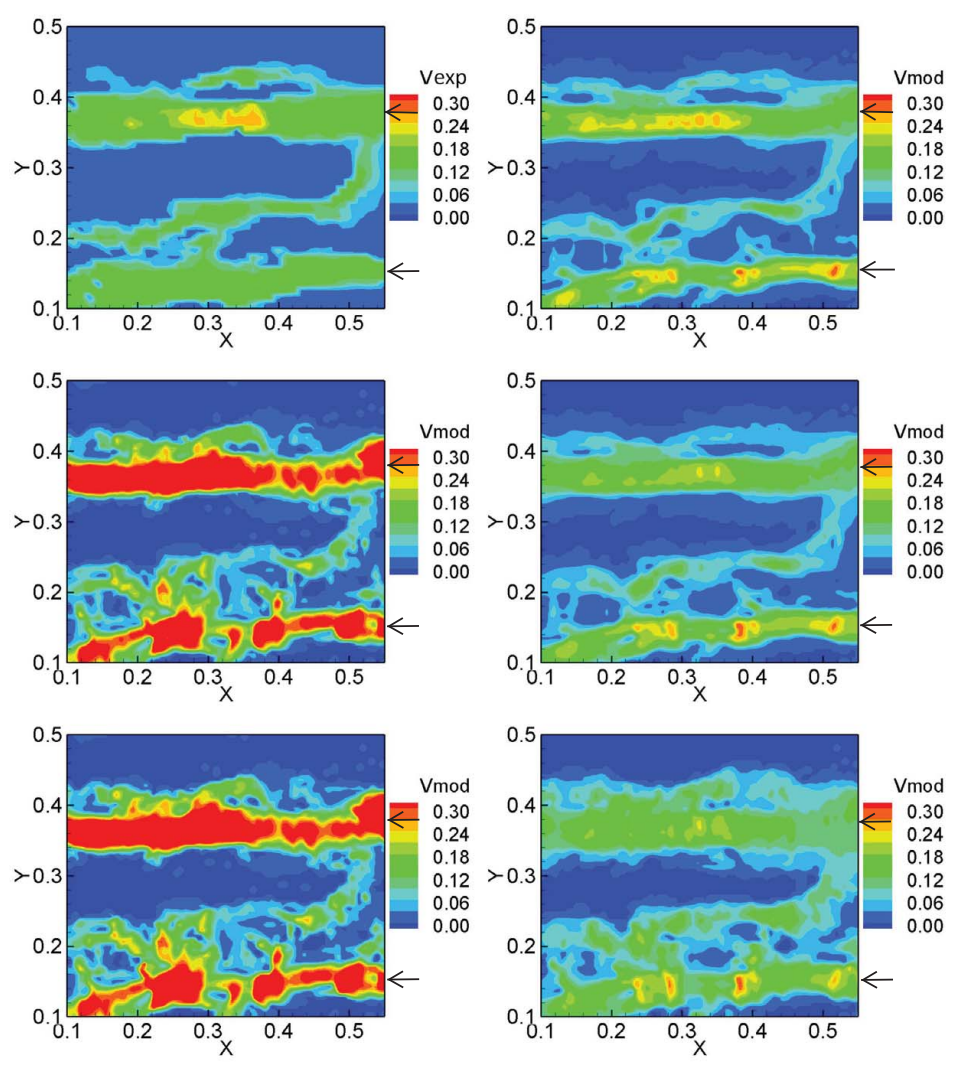

Figure 12: Velocity field $(\mathrm{m} / \mathrm{s})$ in the agricultural mould in the test case A1 using different bed roughness parameterizations. Black arrows indicate inflow locations. Experimental velocity (topleft) vs. numerical velocity computed with $k_{s}=\max \Delta z$ (top-right), $k_{s}=1 \mathrm{~mm}$ (middle-left), $k_{s}=30 \mathrm{~mm}$ (middle-right), $n=0.013 \mathrm{~s} \mathrm{~m}^{-1 / 3}$ (bottom-left) and $n=0.050 \mathrm{~s} \mathrm{~m}^{-1 / 3}$ (bottomright). 

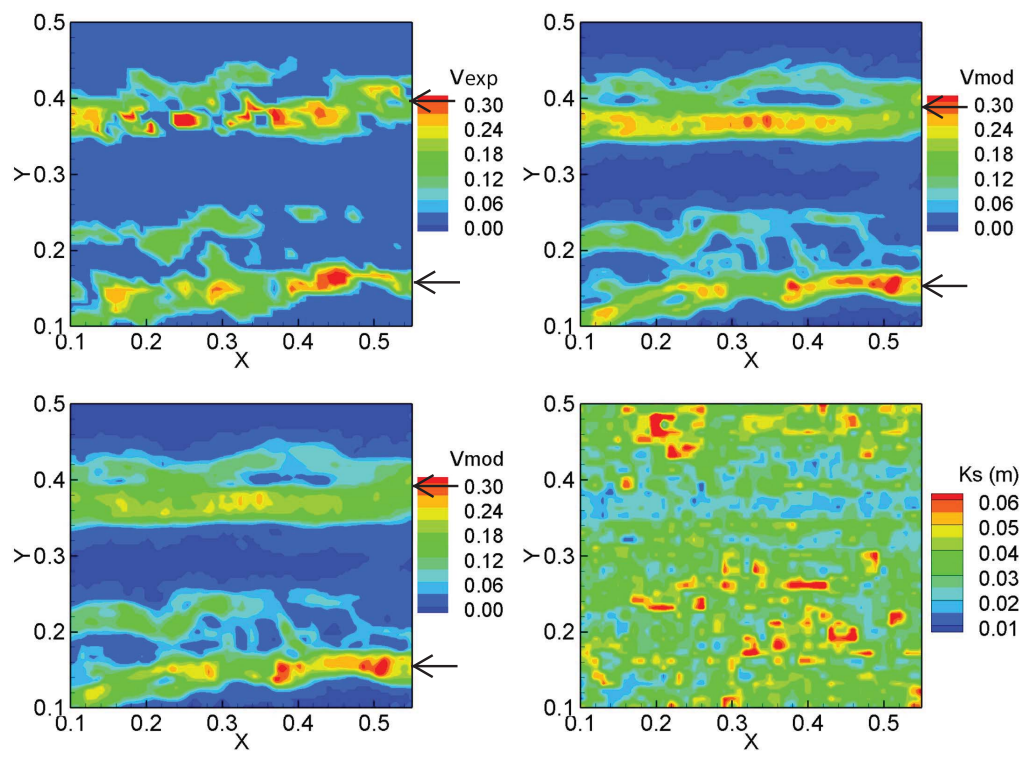

Figure 13: Velocity $(\mathrm{m} / \mathrm{s})$ field in the agricultural mould in the test case A2 using different bed roughness parameterizations. Black arrows indicate inflow locations. Experimental velocity (topleft) vs. numerical velocity computed with $k_{s}=\max \Delta_{z}$ (top-right) and $k_{s}=30 \mathrm{~mm}$ (bottomleft). The bottom-right figure shows the spatial distribution of the roughness height computed from $k_{s}=\max \Delta z$. 